\title{
The Design and Implementation of English Teaching System Based on J2EE Campus Network
}

\author{
Dandan Ding \\ \{dingdandan@126.com\} \\ Department of Foreign Languages Hanjiang Normal University, Shiyan 442000, China
}

\begin{abstract}
Education information engineering is an important measure of education in twenty-first Century. School teaching environmental infrastructure is achieved through the campus network, the campus network is the embodiment of modern education, is the basis and means to achieve quality education. The construction of reliable, manageable, scalable, with advanced, safe campus network, is to adapt to the current development trend of network technology and meet the important basis for the application of all aspects of the university. English as a universal language is any individual and the school can not avoid the subject, now, whether it is in the exam, college entrance examination or grind or some other test, English is almost lesson compulsory subjects. The wide range of English learning, but also to network English more and more English learners need. In this paper, using Server2008 SQL database platform management system, the use of Dreamweaver 8 and JSP technology design and implementation of each module function. The system realizes the education news, books, learning materials and learning video search and view, and online Q \& a module in the user's questions and respond to questions functionality for users to interact. The English teaching system of campus network has set up a set of security, stability, high bandwidth in the integration of campus English teaching network for the Guangdong Institute of physical education. The school overall network connectivity, and students can share a variety of software and hardware resources, providing the various kinds of information exchange and experience to share and discuss the platform to enhance student learning enthusiasm and initiative.
\end{abstract}

Keywords: Campus network; English teaching; video; online question answering

\section{Introduction}

Along with the continuous development of network and multimedia technology computer technology, the resources and applications of computer network are continuously enriched. According to the requirements of management and multimedia technology, the requirements of the construction and management of the campus network are also put forward. Therefore, the construction of a manageable, reliable, advanced, scalable security campus network, to adapt to the current development trend of computer networks, and to meet the needs of all aspects of the campus network construction. The means of school education in the future is based on the development of educational information [1], the goal of the future construction and development: to carry out the network teaching, education information services and distance education services, etc.. The development and popularization of computer multimedia and network technology, in order to promote the development of campus network 
construction, for teachers and students to provide convenient conditions for learning, to create a more convenient learning environment, so that it can be free, convenient and economical acquisition and exchange of network information, the construction of the campus student dormitory and the families of the network, is very necessary, but also feasible. Teachers in their spare time can easily browse and query online resources, teaching and research work; students in their spare time can easily browse and query online resources to achieve distance learning. The use of network learning has many advantages. First of all, the network learning can also realize the sharing of information resources, and, today's society is the fastest way to spread information through the internet. The Internet has become a very important part of modern people's life. Secondly, learning through the network is not restricted by time and region. When users want to learn when to learn, do not have to consider the geographical problem, as long as the user needs to be able to watch some of the famous teacher's lecture video. Especially now that some schools and teachers in order to increase awareness, usually the lecture of the document or video released to the network, so as to provide some learners with more information. Also, English is the common language of the world, according to statistics, about $30 \%$ of the world people have English as their mother tongue, also $50 \%$ of the English as the second language learning, information superhighway "Internet" information close to $80 \%$ is loaded by English, many technical in nature and the scientific nature of literature are also use English writing. Similarly, in China, English is also important, both in the exam, college entrance examination, entrance examination, English is a compulsory courses, the recruitment of many large companies to look for candidates whether CET. As a result, English teaching has been developed as a focus of network teaching because of its universality and popularity [2].

\section{System Technology Foundation}

VLAN technology is based on the physical network division of the network broadcast domain, broadcast storms and channel conflict in the transmission of the transmission of the site, the impact of network performance. In order to solve the second layer channel conflict and third layer broadcast storm problem, the router is used to solve the problem. The interface can be separated by a router. However, the general network interface on the router is very small, generally 1-4 can not be divided according to the needs of the broadcast domain. The network efficiency and security of this kind of structure are both short of. In the network, the site is limited to the physical network, can not be divided into logical subnet, so the lack of flexibility of the network structure, the introduction of virtual LAN to solve this problem. Local Area Network Virtual (virtual local area network) is the network user needs into a number of logical working group, each logical working group is a virtual lan. Virtual LAN based on functional factors, do not need to know the user's address, you can put the user into a logical independent working group, to achieve the location of the distribution. A plurality of devices can be connected to each VLAN through the broadcast domain. 


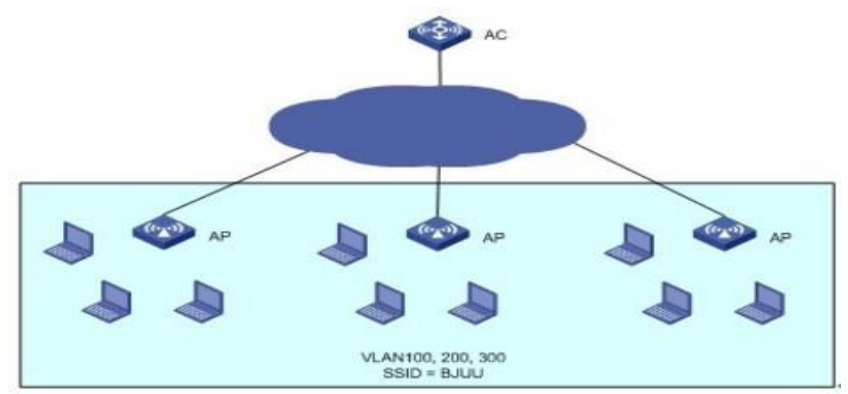

Fig. 1. Schematic diagram of VLAN structure

\subsection{Three Layer Switching Technology}

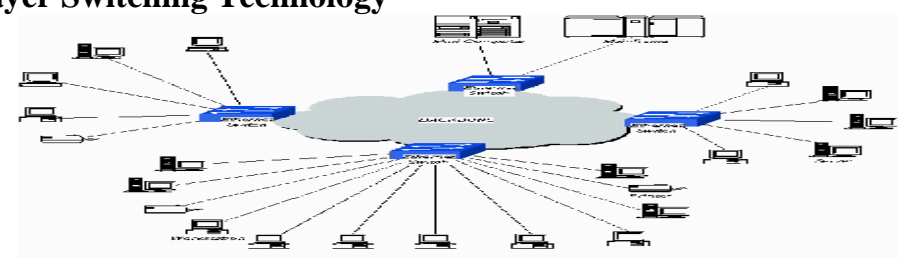

Fig. 2. Schematic diagram of the three layer switching technology

Network core technology of switching and routing technology. The two layer switch is in the data link layer of the seven layer model. It only identifies the information of the layer and does not recognize the network address. But the router can identify the MAC and analyze the information protocol, also can control the communication routing. Router is a software processing, the router software running on the CPU, with the router software for routing, with the traffic increase, the speed of the router can not be forwarded under the speed limit, will become the bottleneck of the network. Two layer switch and router uses ASIC chip, its processing speed is fast. In order to solve the above problems, the third layer switching technology is realized by using router control and switch performance. In the switch to the introduction of independent modules, with the ability to route, VLAN is accessed through the three layer switching technology. The three layer switching technology division network, solves the bottleneck router forwarding algorithm, problem. Through the IP routing technology to achieve data forwarding, improve the performance. Three layer switch can realize the routing function and the internal convergence link [3].

\subsection{Network Technology Selection of Campus Network}

Cascade can be defined as two or more than two switches interconnected by a certain way. Multiple switches can be cascaded in a variety of ways, as needed. In the larger local area network such as the campus network, the multiple switches form a bus type, a tree type or a star cascade structure in accordance with the performance and use. Port security is an MAC address that allows access to a certain port on the switch, and IP (optional) to implement a configuration that controls access to the port strictly. Open the port security port called port security is allowed through security port address called to address security, only from the address of the data flow can pass through the switch so as to prevent network using spoofed 
addresses and generate a variety of attacks. As the heart of the campus network system, the network center node and other core nodes must provide a number of speed changes. When the network traffic is large, the service quality of the key service is guaranteed. In addition, as the exchange center of the whole network, it is necessary to ensure the stability and reliability of the high performance and non blocking switching. The network center and the convergence layer node (kilometer exchange node) are connected with redundant lines, and there are a number of Gigabit links between the core layer switch and the aggregation layer switch [4].

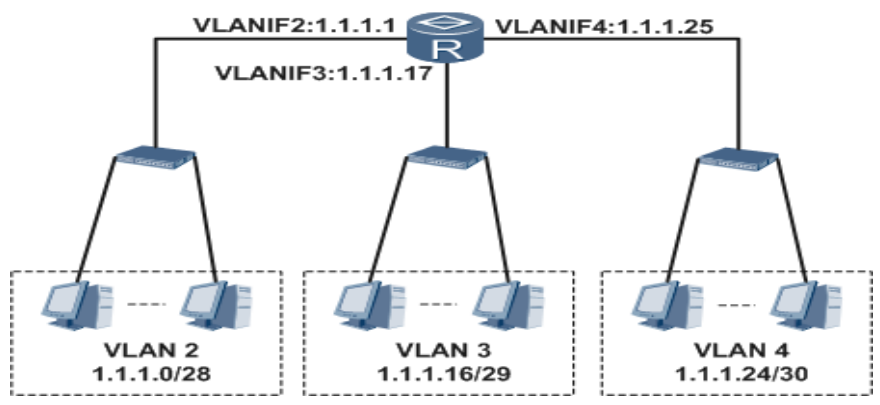

Fig. 3. Sketch map of campus network structure

\subsection{J2EE Technology Analysis}

At the end of the eighties of the last century, the middleware idea put forward and development for the new things provide the framework for and in the early 1990s, the rise of the Internet was created something new to provide the environment for the growth, the birth of the Java language as the provides fertile soil, and business applications increasing, the further maturation of middleware. Finally the application server in the J2EE specification was released, as have sprung up like mushrooms. The application server integrates the advantages of various middleware technologies, provides the system architecture for the new generation of enterprise development, provides the service of distributed objects, transaction processing services, secure access services, and so on. In open source increasingly popular, era of fierce competition, J2EE, whether in the framework of the overall or in some specific techniques are facing the great challenges, challenges faced by the. Net framework), and in the web tier, is relatively mature struts in all kinds of application server and the integration of the IDE provides support struts, struts is mainly through the MVC thought the servlet task more clearly as a controller part, JSP need only take the view in this part of the work, in addition to the business layer provides the bean component or other components as a model, thus in the overall architecture and extracted a three-layer structure.

\section{System Design and Implementation}

A good English teaching website should be able to provide the latest education information to the user, can provide users with rich learning materials and can provide users with a good exchange platform. 1 system of the utility: the system to the user needs as the goal, to facilitate the user as the principle of. According to the actual needs analysis, we should design and implement a resource rich, innovative and can communicate with each other in English 
teaching website, and to provide users with the latest news and resources. From the user's point of view, as far as possible to facilitate the user to use, to meet the basic needs of users, so that it has a practical. And access to the site does not require users to spend any fee for the majority of users to provide a free learning English website, more because of its free sex, more will attract more users to visit the site. 2 system of the advanced nature: the system through the development of computer software, computer network technology to achieve the design of the Russian system, and to provide users with high performance. System through the B/S structure, the use of SQLSERVER database implementation, the use of Eclipse My 7 development tools, to achieve an English teaching website. 3 system security: in the system design, through the software and hardware security measures, to achieve the sharing of data resources for users, to protect the security of users in the database access. 4 system maintenance: maintenance of the design of the system, the main software and hardware maintenance design. For example, the upgrade of the system, etc. 5 system flexibility: the design method of flexibility. System for business expansion, investment protection system. Based on the campus network teaching platform system is the current English learning methods and modern network technology combined, make learning housebound people realize English learning through the website, build a break traditional, not subject to geographical and time constraints of a new model of education. Based on Network English teaching system is a set of interactive website information, learning and communication, which requires the development of website provides information about English learning, so the website must contain the learning of the news information content and related books, video and learning materials and so on [5].

\section{Conclusion}

The Guangdong College of Physical Education Campus Network English teaching system in the actual situation and needs analysis, research and summarizes the experiences and lessons in the process of the current campus network English teaching system construction according to the proposed overall design objectives, design principles, implementation of the solution. The system used in Eclipse SQL, Server My 2008, Dreamweaver 8 and other development tools, while the site is currently used in the construction of the popular Struts framework. Thus greatly enhance the maintainability and scalability of the site. It provides a great convenience for future maintenance. Site is divided into front and back office management of the two major modules. The front display module is divided into six modules: advertising information, education news, book recommendation, learning materials, learning video and online Q \& A. Background management module is divided into advertising information management, information management, information management, information management, learning materials management, learning video management and question answering information management. System after the completion of after the testing phase of the analysis system of main function modules tested the basic realization of the proposal in order to achieve the basic functions of. 


\section{References}

[1] Hu. Summer and implementation of. software design of the examination system based on J2EE. No. 01. (2012)

[2] Ding Zhiping. Design and implementation of remote teaching system based on J2EE architecture. computer and digital engineering. No. 10. (2011)

[3] Liu Zhen, Yang Shengbin, Zhang Jinhong. Design and development of online job management system based on. J2EE computer and modernization. No. 07. (2011)

[4] Liu Yong, Ma Zhixin, Xie Xianzhong. Design and implementation of network aided teaching platform based on open source framework. computer technology and development. No. 12. (2014)

[5] Yang Fuhua, Peng Gang, Pan Hong. Discussion on the application of 802.1X authentication technology in the campus network. China medical education technology. No. 03. (2013) 